\title{
Molecular biology of avian infectious laryngotracheitis virus
}

\author{
Walter FUCHS $^{\text {a* }}$, Jutta VEITS ${ }^{\mathrm{a}}$, Dorothee HELFERICH ${ }^{\mathrm{a}}$, Harald \\ GRANZOW $^{\mathrm{b}}$, Jens P. TEIFKE ${ }^{\mathrm{b}}$, Thomas C. METTENLEITER ${ }^{\mathrm{a}}$ \\ ${ }^{a}$ Institute of Molecular Biology, Friedrich-Loeffler-Institut, Federal Research Institute for Animal \\ Health, Boddenblick 5A, 17493 Greifswald - Insel Riems, Germany \\ ${ }^{b}$ Institute of Infectology, Friedrich-Loeffler-Institut, Federal Research Institute for Animal Health, \\ Boddenblick 5A, 17493 Greifswald - Insel Riems, Germany
}

(Received 6 April 2006; accepted 19 October 2006)

\begin{abstract}
Infectious laryngotracheitis virus (ILTV) is an alphaherpesvirus that causes an economically important chicken disease, which results in delayed growth, reduced egg production, and also frequently in death of the animals. After acute infection of the upper respiratory tract, the virus can establish latency in the central nervous system, and subsequent reactivations can lead to infection of naive chickens. For prevention of ILT, conventionally attenuated live vaccines are available. However, these vaccine strains are genetically not characterized, and reversions to a virulent phenotype occur. Although molecular analyses of ILTV are hampered by the lack of an optimal cell culture system, the complete nucleotide sequence of the ILTV genome has recently been elucidated, and several ILTV recombinants lacking nonessential, but virulence determining genes have been constructed. Animal trials indicated that genetically engineered stable gene deletion mutants are safe alternatives to the current vaccine strains. Furthermore, since live ILTV vaccines are suitable for fast and inexpensive mass administration, they are promising as vectors for immunogenic proteins of other chicken pathogens. Thus, immunization with ILTV recombinants expressing avian influenza virus hemagglutinin was shown to protect chickens against ILT and fowl plague. Using monospecific antisera and monoclonal antibodies several virion proteins of ILTV have been identified and characterized. Since they include immunogenic envelope glycoproteins, these results can contribute to the improvement of virus diagnostics, and to the development of marker vaccines.
\end{abstract}

infectious laryngotracheitis virus / DNA sequence / monoclonal antibodies / recombinant livevirus vaccines / viral vectors

\section{Table of contents}

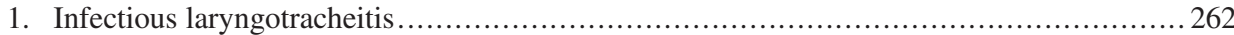

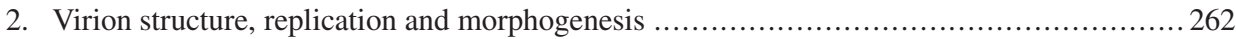

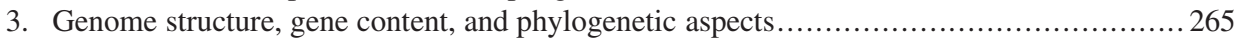

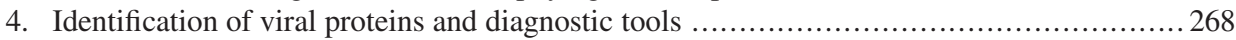

5. Genetically engineered ILTV mutants, and other novel approaches

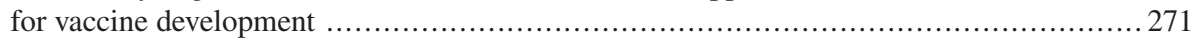

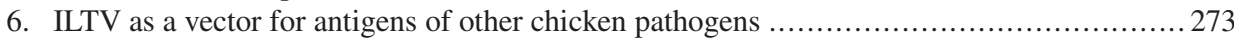

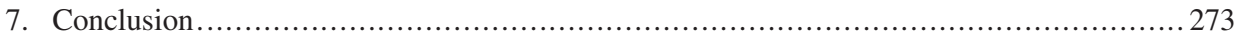

* Corresponding author: walter.fuchs@ fli.bund.de 


\section{INFECTIOUS LARYNGOTRACHEITIS}

Infectious laryngotracheitis (ILT) is a worldwide occurring respiratory disease of chickens, which is caused by a virus designated as ILTV or gallid herpesvirus 1 (GaHV-1). A detailed review on ILT has recently been published [39]. Therefore, clinical and immunological aspects will only be briefly mentioned in the present report. ILT was first described in the USA in 1925 [62], and shortly thereafter its viral aetiology was demonstrated [6]. The severity of clinical symptoms depends on the virulence of a particular strain or isolate, and mortality rates can vary between 0 and more than $70 \%$. Symptoms of milder forms of ILT are nasal discharge, conjunctivitis and reduced egg production, whereas severe forms are additionally characterized by gasping, coughing, expectoration of bloody mucus, and marked dyspnoea (Fig. 1D) which may lead to suffocation. Pathomorphological alterations can be observed in conjunctiva, larynx, trachea, and sometimes also in the lungs (Fig. 2E) and air sacs. The incubation period ranges from ca. 6 to 12 days after natural infection through ocular or respiratory routes, and from 2 to 4 days after experimental intratracheal infection. After an acute phase of ca. 7 days, ILTV can establish lifelong latent infections in the central nervous system, in particular within the trigeminal ganglion $[4,96]$. Sporadic reactivations are mostly inapparent, but lead to productive replication in the respiratory tract and virus shedding, which can result in infection of susceptible contact animals [44].

ILTV infection of chickens frequently induces production of virus-neutralizing antibodies [42], but antibody titers correlate only poorly with protective immunity $[8,84]$. Furthermore, bursectomized animals, although unable to produce ILTVspecific antibodies, were protected against reinfection, indicating a dominant role of cell-mediated immune responses [22]. Nevertheless, ILTV-specific antibodies can be used for serological diagnosis by virus neutralization, agar-gel immunodiffusion, indirect immunofluorescence, and enzyme linked immuno sorbent assays (ELISA) [42, 43, 50, 68]. The ELISA technique has also been used for detection of viral proteins in tracheal exudates [98]. However, more recently protein detection by immunoperoxidase tests, and DNA detection by conventional polymerase chain reaction (PCR) or real-time PCR have become preferred methods of virus diagnosis $[1,16$, $38,54,81,96]$. In combination with analyses of restriction fragment polymorphisms and DNA sequencing the PCR technique also facilitates differentiation of virus isolates for epidemiological and phylogenetic studies [16,54].

For prevention of ILT, live-virus vaccination has been in use for many decades. Early after discovery of the disease, chickens were immunized by cloacal application of virulent virus [9]. Later, virulent field strains of ILTV were attenuated by passage in embryonated chicken eggs or cell cultures $[29,77]$. The obtained vaccine strains can be administered individually by eye drop, but are also suitable for mass application via aerosol or drinking water [39]. Most of these vaccines are efficacious, but many of them possess considerable residual virulence, which can further increase during animal passages $[37,58]$. Thus, several outbreaks of ILT have been attributed to revertant vaccine strains $[3,36]$.

\section{VIRION STRUCTURE, REPLICATION AND MORPHOGENESIS}

Electron microscopy revealed that ILTV particles exhibit the typical morphology of herpesvirions (Figs. 2A, 2B, 3), consisting of a DNA-containing core within an icosahedral capsid which is surrounded by a 

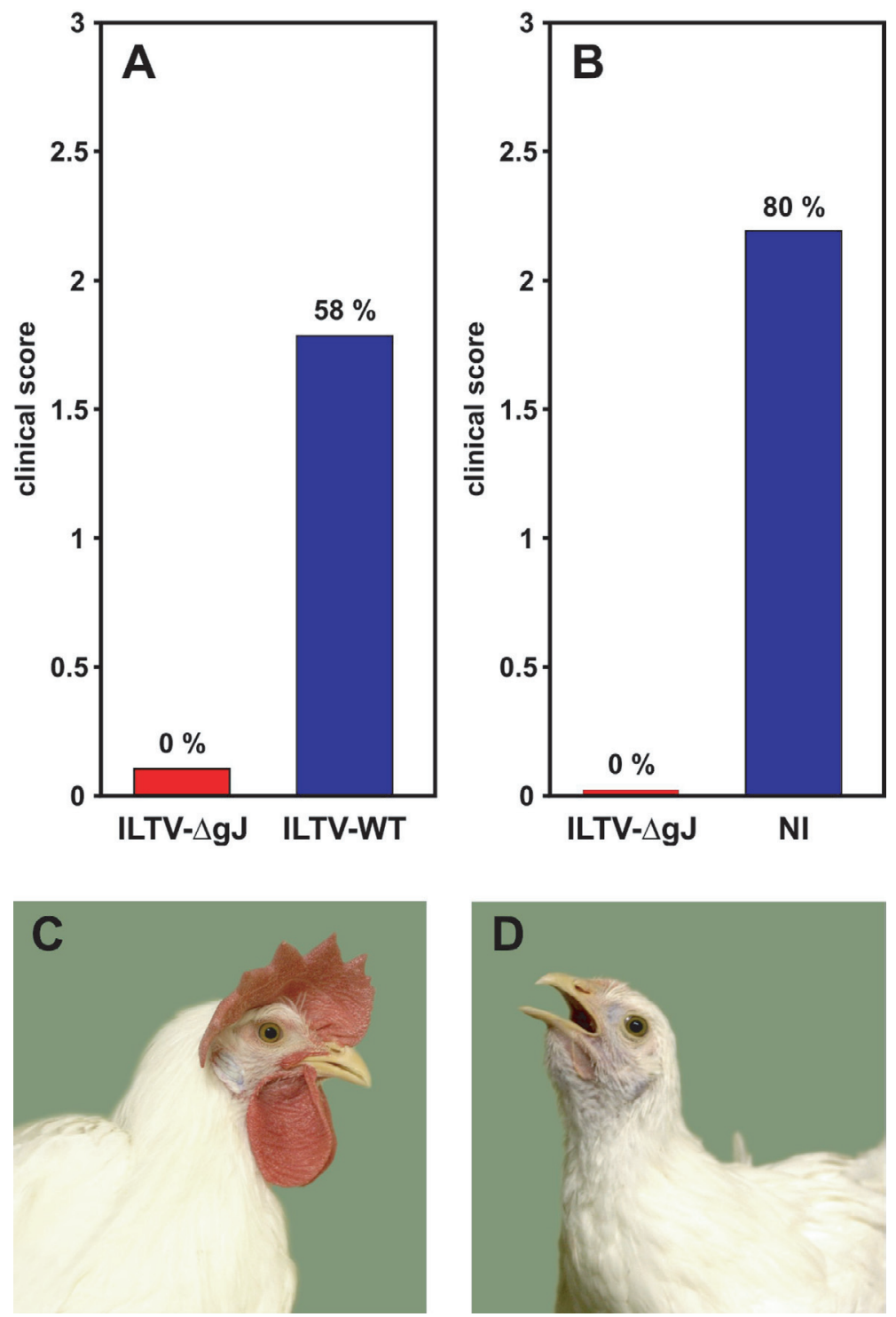

Figure 1. Safety and efficacy of live-virus vaccination with gJ-negative ILTV. (A) Eight-week old chickens were infected by intratracheal administration of $2 \times 10^{4}$ plaque forming units (PFU) of ILTV- $\Delta \mathrm{gJ}$ or wild-type ILTV (ILTV-WT). (B) After four weeks, immunized and naïve (NI) animals were challenged with $10^{5}$ PFU of ILTV. From days 1 to 10 after each infection the animals were daily classified as healthy (0), ill (1), severely ill (2), or dead (3). The cumulative clinical scores for each group were plotted and mortality rates $(\%)$ are indicated. The pictures show a protected chicken (C) and a control animal suffering from severe dyspnea (D) at day 4 after challenge. For more details see reference [26]. (A colour version of this figure is available at www.edpsciences.org/vetres.) 

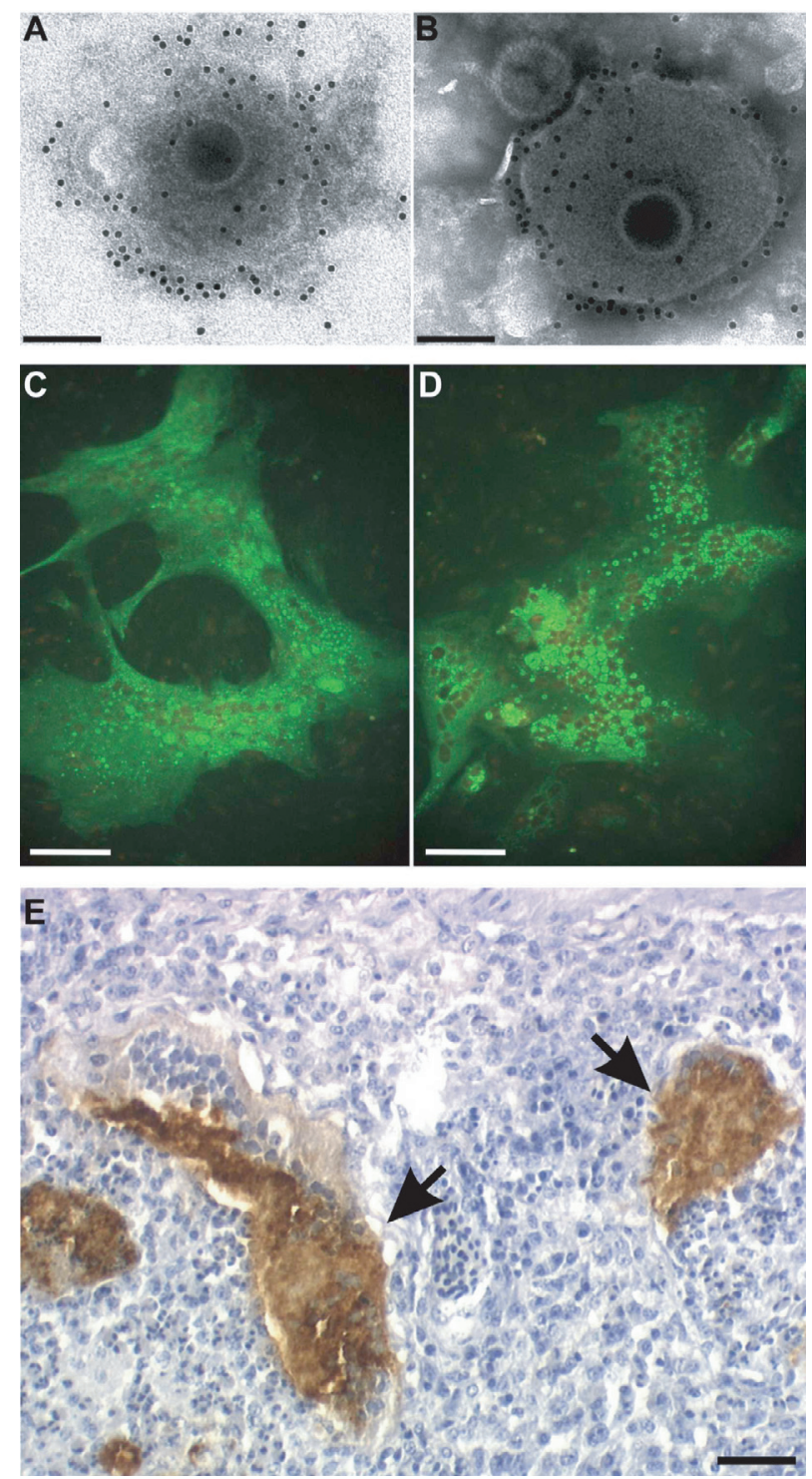

Figure 2. Reactivity of monoclonal antibodies against ILTV glycoproteins gC (A, C) and gJ (B, D, E). For immunoelectron microscopy (A, B) MAb binding to purified ILT virions was detected by gold-tagged secondary antibodies. Virus particles were stained with phosphotungstic acid. For indirect immunofluorescence tests (C, D) chicken embryo kidney cells were fixed $24 \mathrm{~h}$ after infection with methanol and acetone (1:1). MAb binding was detected with fluorescein-conjugated secondary antibodies, and chromatin was counterstained with propidium iodide. Immunohistochemical staining of a lung section from an ILTV-infected chicken (E) was performed by the ABC method. A gJ-specific MAb detected viral antigen in the cytoplasm of several syncytia (arrows). Bars represent $150 \mathrm{~nm}(\mathrm{~A}, \mathrm{~B}), 100 \mu \mathrm{m}(\mathrm{C}, \mathrm{D})$, and $50 \mu \mathrm{m}(\mathrm{E})$. (A colour version of this figure is available at www.edpsciences.org/vetres.) 
proteinaceous tegument layer and an outer envelope with incorporated viral glycoproteins $[17,75,94]$. Whereas all capsids have diameters of ca. $100 \mathrm{~nm}$, particle sizes vary between 200 and $350 \mathrm{~nm}$, since ILTV tends to incorporate huge amounts of tegument proteins [30].

Like other avian herpesviruses, ILTV exhibits a very narrow host range both in vivo and in vitro. Besides domestic chickens, pheasants represent the only natural hosts [39]. Furthermore, the virus could be isolated from peafowl [15], and experimental infections of turkeys have also been described [97]. In vitro, ILTV can be propagated on the chorioallantoic membrane of embryonated chicken eggs [10], and in primary kidney and liver cells of chickens or chicken embryos $[12,63]$. Up to now, only one permanent cell line $(\mathrm{LMH})$ derived from a chemically induced chicken liver tumor was shown to permit replication of ILTV $[51,78,80]$. However, the resulting virus titers were significantly lower than in primary cells. After several hours, ILTV infection of permissive chicken cells induces formation of syncytia and nuclear inclusion bodies [73], and subsequent lysis of the cells leads to plaque formation after 3 to 5 days.

The replication cycle of ILTV has only been poorly investigated up to now, but appears to be similar to that of other alphaherpesviruses like herpes simplex virus type 1 (HSV-1) [74]. One-step growth analyses in primary chicken kidney cells revealed that first infectious progeny viruses are formed 8 to $12 \mathrm{~h}$ after infection, and reach a maximum after 24 to $30 \mathrm{~h}$ [25]. Metabolic labeling of proteins in ILTV-infected cells in combination with inhibitors of translation or DNA replication indicated a cascadelike regulation of viral gene expression as is typical for herpesviruses [72], and transfection experiments with expression plasmids for the ILTV homologues of the major HSV-1 transcription activators VP16 and ICP4 revealed similar transactivating functions $[25,41]$.

Ultrastructural analyses of ILTVinfected cells showed the typical steps of herpesvirus morphogenesis (Fig. 3) $[30,35,67]$. In the nucleus, capsids are formed and filled with viral DNA (Figs. 3A, 3C). Then, the nucleocapsids are transported into the cytoplasm by subsequent envelopment and deenvelopment at the inner and outer leaflets of the nuclear membrane (Figs. 3B, 3C). The cytoplasmic capsids associate with electron dense tegument, and are then re-enveloped by a second budding event in the trans-Golgi region (Figs. 3D, 3E), followed by release of mature particles by exocytosis (Figs. 3F, 3G). Uncommon features frequently observed in ILTVinfected cells are the formation of tubular structures of unknown function, and of large cytoplasmic vacuoles containing numerous virions [35]. Furthermore, besides few complete virions, many light (L) particles are formed, which consist of tegument and envelope, but do not contain nucleocapsids (Fig. 3D) [30]. Presumably, these erroneous structures are in part responsible for the low titers of ILTV in tissue culture, which barely exceed one infectious unit per cell.

\section{GENOME STRUCTURE, GENE CONTENT, AND PHYLOGENETIC ASPECTS}

Restriction analyses revealed that the linear double-stranded DNA genome of ILTV consists of two unique regions $\left(\mathrm{U}_{\mathrm{L}}\right.$, $\mathrm{U}_{\mathrm{S}}$ ), and of inverted repeat sequences (IR, TR) flanking the $\mathrm{U}_{\mathrm{S}}$-region (Fig. 4) $[45,60]$. Similar structures, which allow formation of two genome isomers with differently oriented $U_{S}$-regions, have also been found for many other alphaherpesviruses, and designated as type D herpesvirus genomes [75]. First sequence 


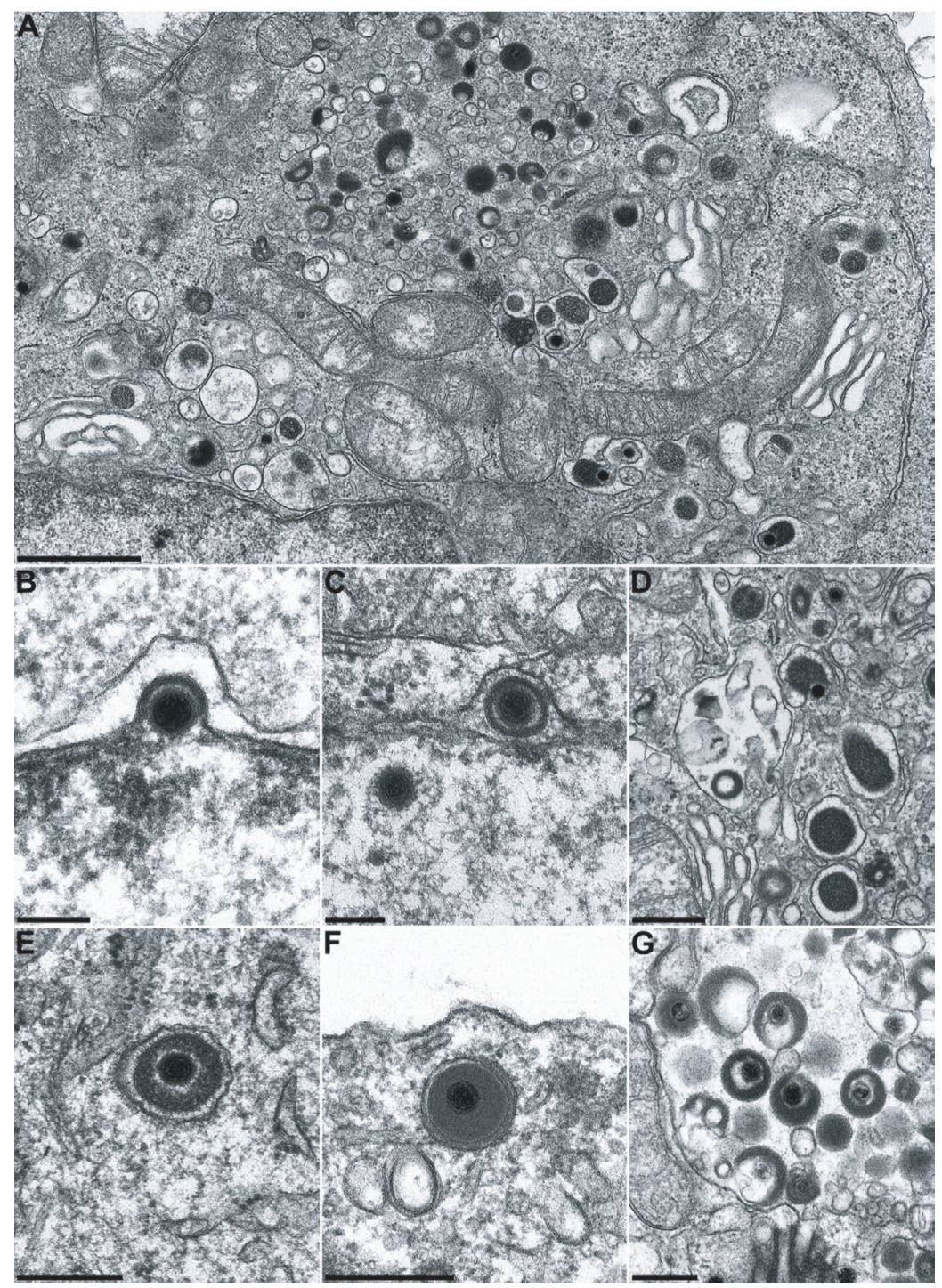

Figure 3. Electron microscopy of ILTV morphogenesis. Chicken hepatoma (LMH) cells were fixed and embedded $18 \mathrm{~h}$ after infection, and ultrathin sections were stained with uranyl acetate and lead salts. The micrographs show nuclear egress by primary envelopment of capsids at the nuclear membrane (B, C), and formation of mature and capsid-less particles by assembly of tegument and secondary envelopment in the trans-Golgi region of the cytoplasm (D, E). Virions are released from cells by exocytosis (F, G). Bars represent $1 \mu \mathrm{m}$ (A), $500 \mathrm{~nm}$ (D), $300 \mathrm{~nm}$ (E, F, G), or $150 \mathrm{~nm}$ (B, C). 


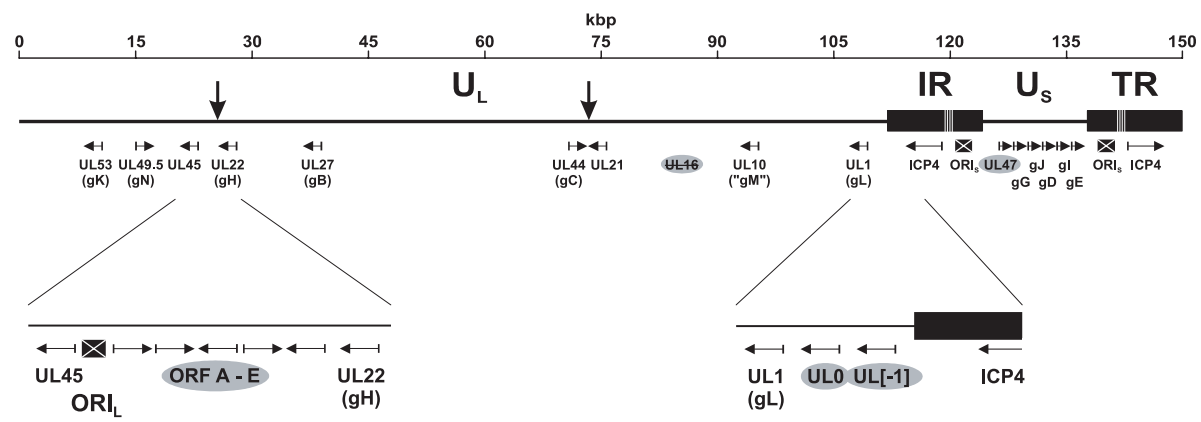

Figure 4. Map of the double-stranded DNA genome of ILTV, which is ca. $150 \mathrm{kbp}$ in size and consists of long and short unique regions $\left(\mathrm{U}_{\mathrm{L}}, \mathrm{U}_{\mathrm{S}}\right)$, and of inverted repeats (IR, TR) flanking the $\mathrm{U}_{\mathrm{S}^{-}}$ region. The IR- and TR-regions contain variable copy numbers of direct repeat elements (vertical lines). Compared to most other alphaherpesvirus genomes, a part of the $\mathrm{U}_{\mathrm{L}}$ region is inverted (bordered by vertical arrows). Origins of DNA replication $\left(\mathrm{ORI}_{\mathrm{L}}, \mathrm{ORI}_{\mathrm{S}}\right)$ and selected genes (horizontal arrows), including those of conserved glycoproteins ( $\mathrm{gB}$ to $\mathrm{gN}$ ) are indicated. Enlarged sections show two clusters of Iltovirus-specific genes (ORF A - E, UL0, UL(-1)). Other specific features of ILTV are the translocation of UL47 to the $\mathrm{U}_{\mathrm{S}}$ region, and the absence of an UL16 homologue (highlighted).

data of ILTV DNA became available in the late 1980s [31]. In the meantime, a complete sequence of the whole genome has been assembled from overlapping genome fragments of different virus strains analyzed in numerous laboratories [23-25, 32-34, 46, 48, 49, 52, 55$57,70,87,95,101,102]^{1,2}$. The resulting molecule encompasses 148687 base pairs (bp), and contains ca. $48.2 \% \mathrm{G}$ and $\mathrm{C}$ residues. For several genome regions more than one sequence is available, which in some cases exhibit considerable differences. Most strikingly, close to the left genome end the Australian vaccine strain SA-2 contains an insertion of 3575 bp (nucleotides 2173 to 5747 of the published genome sequence), which is absent from the genome of the virulent ILTV strain A $489^{3}$ [49]. Another feature contributing to size variation of the ILTV genome is a direct repeat element of 856 bp which ex-

\footnotetext{
${ }^{1}$ Johnson M.A., 1999, GenBank \# AF168792.

${ }^{2}$ Kehu Y., Manfu Z., Yiping L., 2001, GenBank \# AY033143.

${ }^{3}$ Fuchs W. et al., unpublished results.
}

ists in tandem arrays of 1 to 13 copies in the IR- and TR sequences (Fig. 4) [95]. Like many other alphaherpesviruses ILTV possesses three origins of viral DNA replication, one $\left(\mathrm{Ori}_{\mathrm{L}}\right)$ located within the $\mathrm{U}_{\mathrm{L}^{-}}$ genome region, and two copies of another (Ori ${ }_{S}$ ) within the IR and TR sequences, respectively (Fig. 4) ${ }^{4}$ [101]. In ILTV, these elements contain exceptionally long palindromic regions, which hamper cloning and DNA sequencing. This might explain why Oris has not been detected in earlier studies, and has not been included in the published genome sequence of ILTV [87].

The gene content of ILTV clearly confirms its previous classification as an alphaherpesvirus [19]. The ILTV genome contains 76 open reading frames (ORF) which have been predicted or demonstrated to encode proteins [87]. Sixty-three of these ORF exhibit homologies to genes of the prototypic alphaherpesvirus HSV-1 [64], at least with respect to genome position and overall structure of the deduced translation products. Eleven of the conserved

\footnotetext{
${ }^{4}$ Fuchs W., 2006, GenBank \# AM238250.
} 
ORF encode homologues of the HSV-1 glycoproteins $\mathrm{gB}, \mathrm{gC}, \mathrm{gD}, \mathrm{gE}, \mathrm{gG}, \mathrm{gH}$, gI, gJ, gK, gL and gM (Fig. 4). For clarity, the commonly used HSV-1 gene designations UL1 to UL54, US2 to US8, and US10 were also adopted for ILTV (Fig. 4). Between the UL2 and UL3 homologues the ILTV genome contains an additional ORF (UL3.5) which is not present in herpes simplex virus genomes, but conserved in most other mammalian and avian alphaherpesviruses [23]. Moreover, the ILTV genome exhibits several unique characteristics, as e.g. the absence of an UL16 homologue [24]. This protein is otherwise conserved throughout all herpesvirus subfamilies, although its function remains largely enigmatic [74]. The gene encoding a major tegument protein, UL47, is usually localized within the $\mathrm{U}_{\mathrm{L}}$ genome region of alphaherpesviruses [64], but absent at the corresponding position of ILTV DNA [101]. However, a significantly conserved homologue of UL47 was found to be inserted between the US3 and US4 genes within the $\mathrm{U}_{\mathrm{S}}$ genome region of ILTV [95]. Besides this translocation, compared to most other alphaherpesviruses the ILTV genome also exhibits a large internal inversion of a conserved gene cluster within the $\mathrm{U}_{\mathrm{L}}$ region (Fig. 4) [101]. This inversion includes the UL22 to UL44 genes, and, thus, is similar to a previously described inversion of the UL27 to UL44 gene region within the genome of the porcine alphaherpesvirus pseudorabies virus (PrV) [7]. However, it is unclear whether these findings indicate a special phylogenetic relationship between ILTV and PrV, or whether they reflect two independent events. Recently, an inversion within the $\mathrm{U}_{\mathrm{L}}$ genome region identical to that in ILTV, as well as a translocation of UL47, have also been found in the genome of psittacid herpesvirus 1 (PsHV-1), the causative agent of Pacheco's disease of parrots [87]. This virus represents the closest cognate of ILTV identified up to now, since it also possesses homologues of several open reading frames which have so far been considered as unique for ILTV. Besides several poorly conserved genes within the $U_{S}$ region and adjoining parts of the IR- and TR sequences [95] a cluster of five ILTV- and PsHV-1-specific ORF (ORF A to ORF E) is localized in the $\mathrm{U}_{\mathrm{L}}$ genome region $[87,101]$. Whereas ORF A to ORF E share no significant homology with any other known viral or cellular genes, marked similarities were detected between the deduced amino acid sequences of another two ILTV-specific genes designated as UL0 and UL(-1), suggesting that these genes presumably result from an ancient duplication event [102]. Interestingly, the genome of PsHV-1 apparently contains only one of these genes, UL(-1) [87].

The presence of several genes specific for ILTV and PsHV-1 already indicated that these viruses might represent a separate branch within the phylogenetic tree of herpesviruses. This was also confirmed by comparative analyses based on the amino acid sequences of conserved gene products $[47,65]$. These studies revealed that the ancestors of ILTV probably separated from those of the mammalian alphaherpesviruses even earlier than the ancestors of Marek's disease virus (MDV) and herpesvirus of turkeys. Therefore, ILTV has been assigned as the hitherto only member to the genus Iltovirus of the Alphaherpesvirinae subfamily of the Herpesviridae [19]. However, considering the recently published sequence of the PsHV-1 genome [87], this virus should also be grouped into the same genus.

\section{IDENTIFICATION OF VIRAL PROTEINS AND DIAGNOSTIC TOOLS}

Monoclonal antibodies (MAb) against ILTV particles have been prepared in several laboratories $[2,90,99]$. However, since 
Table I. Identified gene products of ILTV.

\begin{tabular}{lcccc}
\hline Gene & Protein & Amino acids Expected masses (kDa) & Apparent masses (kDa) \\
\hline UL0 & ILTV-specific, nuclear protein & 506 & 57.0 & 63 \\
UL(-1) & Iltovirus-specific, nuclear protein & 501 & 57.6 & 73 \\
ORF A & Iltovirus-specific protein & 376 & 41.3 & 40 \\
ORF B & Iltovirus-specific protein & 340 & 38.1 & 34 \\
ORF C & Iltovirus-specific protein & 354 & 37.4 & 38,30 \\
ORF D & Iltovirus-specific protein & 374 & 41.5 & 41 \\
ORF E & Iltovirus-specific protein & 411 & 45.1 & 44 \\
UL10 & gM homologue, envelope protein & 393 & 43.1 & 36,31 \\
UL22 & gH, envelope glycoprotein & 804 & 89.4 & 92 \\
UL27 & gB, envelope glycoprotein & 883 & 100.2 & $110,100,58$ \\
UL31 & nuclear protein & 314 & 35.4 & 33 \\
UL37 & tegument protein & 1022 & 113.0 & 112 \\
UL44 & gC, envelope glycoprotein & 414 & 46.4 & 60 \\
UL46 & tegument protein & 557 & 62.7 & 64 \\
UL47 & tegument protein & 623 & 70.0 & 66 \\
UL48 & tegument protein & 396 & 44.6 & 45 \\
UL49 & tegument protein & 266 & 30.4 & 34 \\
UL49.5 & gN, envelope glycoprotein & 117 & 12.7 & 17 \\
US4 & gG, secreted glycoprotein & 292 & 31.7 & 52 \\
US5 & gJ, envelope glycoprotein & 985,611 & $106.5,66.8$ & $200,160,115,85$ \\
\hline
\end{tabular}

Protein sizes and molecular masses of primary translation products were deduced from GenBank DNA sequences NC_006623, AM083948 (UL31), and AM083949 (UL37). Apparent masses of viral proteins were determined by Western blot analyses ${ }^{3}[24,26,27,41,71,90,91,102]$.

cloned virus DNA and sequence data were limited in the past, identification of the viral target proteins was difficult. The genes of two viral envelope glycoproteins, designated as $\mathrm{gB}$ and gp60, were detected by screening of lambda-phage expression libraries of cloned ILTV DNA with MAb $[55,57]$. However, a more detailed characterization of the respective viral gene products revealed considerably different molecular masses than described initially [71, 90]. Thus, up to now, only two ILTV proteins, $\mathrm{gC}$ and $\mathrm{gJ}$, could be unambiguously identified as targets of MAb by transient expression of the respective UL44 and US5 genes in eukaryotic cells [90]. The MAb against these two proteins were suitable for indirect immunofluorescence tests, immunohistochemistry, immunoelectron microscopy, radioimmunoprecipitations and Western blot analyses (Fig. 2).
In the latter assays the N-glycosylated envelope protein $\mathrm{gC}$ of ILTV exhibited an apparent molecular mass of $60 \mathrm{kDa}[52$, 90]. The protein is conserved throughout the alphaherpesvirus subfamily, and usually plays an important role during initial virus attachment by binding to heparan sulfate chains of proteoglycans at the host cell membrane [74]. However, obviously neither $\mathrm{gC}$, nor other envelope proteins of ILTV bind to heparin, indicating that this particular virus adsorbs to cells by mechanisms different from those used by most other herpesviruses [53].

At least with respect to antibody responses in mice, the most immunogenic surface protein of ILT virions seems to be the product of the ORF5 gene within the $\mathrm{U}_{\mathrm{S}}$ genome region [95], which was detected by numerous MAb from different laboratories. This protein was initially 
designated as gp60 [57], but later renamed gJ like the glycoprotein encoded at the corresponding genome position of $\mathrm{HSV}-1$ [90]. This gene is missing in most other alphaherpesvirus genomes, but in equine herpesvirus 1 a positional homologous ORF also encodes an immunodominant envelope glycoprotein (gp2) $[85,86]$ which exhibits significant amino acid sequence homology to ILTV gJ. The precise function of ILTV $\mathrm{gJ}$ is still unknown, but it displays interesting characteristics, e.g. multiple protein forms with apparent masses of $85,115,160$ and $200 \mathrm{kDa}$. Two different primary translation products are formed from non-spliced and spliced mRNA, modified by $\mathrm{N}$ - and O-linked glycosylation, and presumably further processed by proteolytic cleavage [26].

While the target proteins of other ILTVspecific MAb remain to be characterized, many viral gene products could be identified after expression in bacteria or other heterologous systems, and preparation of monospecific antisera (Tab. I). Using such an antiserum, the envelope glycoprotein $\mathrm{gB}$ of ILTV was shown to be processed by addition of $\mathrm{N}$-linked carbohydrate chains and by proteolytic cleavage into two subunits, as it has also been described for the $\mathrm{gB}$ polypeptides of most other herpesviruses [71]. Whereas the functional form of $\mathrm{gB}$ seems to be homodimeric, the glycoproteins $\mathrm{gM}$ and $\mathrm{gN}$ of many herpesviruses have been shown to form a heterodimeric complex. This has recently been confirmed for the corresponding UL10 and UL49.5 gene products of ILTV [27]. However, whereas the UL49.5 proteins of ILTV and several other viruses are O-glycosylated (and, therefore, named $\mathrm{gN}$ ), the UL10 protein of ILTV, unlike all known gM homologues, is apparently not modified by glycosylation [24]. Another conserved glycoprotein identified in ILTV is the US4 gene product $\mathrm{gG}$, which, like $\mathrm{gG}$ homologs of several other alphaherpesviruses, is not incorporated into virus particles but secreted from infected cells, and, therefore, might possess immunomodulating functions [56]. Furthermore, the UL22 gene product $\mathrm{gH}$, the major tegument proteins encoded by UL37, UL46, UL47, UL48, and UL49, and the non-structural UL31 protein of ILTV were also identified using monospecific antisera (Tab. I) $[41]^{3}$.

As mentioned above, detailed investigation of ILTV demonstrated the large biological variability within the herpesviruses. Thus, the identification and localization of ILTV- or Iltovirus-specific gene products with monospecific antisera could shed more light on specific characteristics of this genus. It has already been shown that ORF A to ORF E, as well as the ULO and UL(-1) genes of ILTV are translated into proteins, which were detectable by Western blot analyses of infected cells (Tab. I) [91, 102]. However, more detailed studies were hampered by the low expression levels of most of these proteins. Only the related UL0 and UL(-1) proteins, which are both translated from spliced mRNA, could be shown to accumulate in the nuclei of ILTV-infected cells [102]. This localization might indicate functional similarities to the transcription-regulating ICP0 proteins encoded at corresponding genome positions of other alphaherpesviruses [74].

The available monoclonal and monospecific antibodies against defined ILTV proteins may be helpful tools for in situ investigations of the viral replication cycle by immunofluorescence or immunoelectron microscopy. On the other hand, these antibodies can also be used for diagnostic virus detection in tissue samples or tracheal swabs of ILTV infected chickens [1, 38, 90, 98]. ILTV-specific MAb might also facilitate serological diagnosis by indirect or blocking ELISA tests, similar to those that are already applied e.g. for infectious bovine rhinotracheitis, or Newcastle disease of chickens $[18,59]$. In particular, the ILTV gJ- and gC-specific MAb might 
be suitable for this type of assay, since naturally or experimentally infected chickens produce antibodies against these two glycoproteins, which are detectable by indirect immunofluorescence tests on cells expressing the cloned genes $[26,90]$. It was further shown that bacterial fusion proteins expressed from the cloned gJ (gp60) or $\mathrm{gE}$ genes of ILTV can be used as antigens for detection of ILTV-specific serum antibodies in direct ELISA tests [13].

\section{GENETICALLY ENGINEERED ILTV MUTANTS, AND OTHER NOVEL APPROACHES FOR VACCINE DEVELOPMENT}

Since many years, classically attenuated live-virus vaccines are in use for the prevention of ILT in chickens [39]. However, many of them possess residual virulence, which can further increase during animal passages (see above). To overcome this problem, inactivated whole-virus vaccines and subunit preparations containing affinity-purified glycoproteins were successfully tested as alternatives [5, 100]. However, due to the high costs of production and delivery these vaccines are not suitable for immunization of large chicken flocks. Thus, the development of genetically engineered live-virus vaccines against ILT appears more promising. In one approach, immunogenic envelope proteins of ILTV were expressed in the avian virus vectors herpesvirus of turkeys or attenuated fowlpox virus, and the obtained virus recombinants were shown to protect experimentally immunized chickens against subsequent challenge infections with virulent ILTV $[20,76,88]$. However, unlike conventional ILT live-virus vaccines, these virus recombinants require individual administration, and are not suitable for mass application.

Therefore, it was also attempted to generate stably attenuated ILTV mutants by directed deletion of virulence-determining genes. The successful construction of ILTV recombinants could also provide deeper insights into fundamental mechanisms of virus replication, but is still hampered by the lack of suitable cell lines for efficient in vitro propagation and manipulation. Whereas many herpesvirus genomes, including that of the chicken pathogen MDV, have in the meantime been cloned as infectious bacterial artificial chromosomes (BAC) and mutagenized in Escherichia coli $[66,82]$, this technique has not yet been successfully applied to ILTV. A possible reason for this failure is the presence of several long palindromic DNA sequences within the ILTV genome (see above), which are known to be unstable in E. coli [14]. Nevertheless, infectious ILTV could be recovered after transfection of chicken hepatoma (LMH) cells with virion DNA, and virus yields were further increased by simultaneous expression of the viral transcription activators ICP4 or UL48 of ILTV [25]. The infectivity of genomic ILTV DNA allowed the generation of virus mutants by homologous recombination with cotransfected transfer plasmids which carried the desired deletions or insertions. To facilitate the timeconsuming selection and isolation of ILTV recombinants, reporter genes encoding $\beta$ galactosidase or green fluorescent protein (GFP) have frequently been inserted into the virus genome [24, 69, 79]. However, at least in ILTV, these reporter gene insertions might be unstable, or impair viral replication [25], and, therefore, should be removed from the viral genome by a second recombination step.

To our knowledge, up to now fourteen genes were successfully deleted from the ILTV genome (Tab. II). All of them are dispensable for virus replication in cell culture, since construction of transcomplementing chicken cell lines that would permit propagation of ILTV recombinants lacking essential genes, appears to 
Table II. In vitro and in vivo replication properties of ILTV recombinants.

\begin{tabular}{lccc}
\hline Deleted gene & Protein function & In vitro growth defects & In vivo attenuation \\
\hline UL0 & nuclear protein & + & ++ \\
ORF A & unknown & + & n.t \\
ORF B & unknown & + & n.t. \\
ORF C & unknown & + & n.t. \\
ORF D & unknown & + & n.t. \\
ORF E & unknown & + & n.t. \\
UL10 & "gM", envelope protein & + & n.t. \\
UL21 & unknown & ++ & n.t. \\
UL23 & thymidine kinase & - & + \\
UL47 & tegument protein & + & + \\
UL49.5 & gN, envelope glycoprotein & ++ & n.t. \\
UL50 & dUTPase & - & + \\
US4 & gG, secreted glycoprotein & - & + \\
US5 & gJ, envelope glycoprotein & ++ & ++ \\
\hline
\end{tabular}

The degrees of in vitro growth defects and in vivo attenuation observed after deletion of the indicated genes $^{3,5}[24-27,40,41 \mathrm{bis}, 61,79,91,92]$ were estimated as moderate $(+)$, or pronounced $(++)$, since standardized experiments would be required for precise evaluation. (-) No effect; (n.t.) not tested.

be very difficult. Remarkably, deletion of the five Iltovirus-specific genes ORF A to ORF E did not result in severe replication defects with respect to plaque formation or maximum virus titers in cultured cells [91]. Thus, these genes apparently do not represent crucial adaptations to avian host cells, although more important functions during infection of chickens cannot be excluded. Deletion of the ILTV-specific UL0 gene also caused only minor in vitro growth defects, whereas isolation of ILTV mutants lacking the adjacent UL(-1) gene was not possible [92]. This finding indicates that UL0 and UL(-1), although structurally related, are not functionally equivalent.

The conserved herpesvirus genes deleted from the ILTV genome include UL23 and UL50 encoding two functional enzymes of nucleotide metabolism, thymidine kinase (TK) [40,69,79], and dUTPase [25], respectively. Since most host cells possess enzymes with similar activity, the two genes are dispensable for replication of ILTV and other herpesviruses analyzed so far. The glycoproteins $\mathrm{gG}, \mathrm{gJ}, \mathrm{gM}$ and $\mathrm{gN}$, as well as the tegument proteins encoded by UL21 and UL47 were also shown to be nonessential in different alphaherpesviruses including ILTV [24, $26,27,41 \mathrm{bis}]^{3}$. In contrast, recent attempts to delete glycoproteins $\mathrm{gE}$ and $\mathrm{gI}$ did not lead to viable recombinants, indicating that these proteins might be essential for ILTV replication [21].

Several of the described gene deletion mutants of ILTV have already been tested in animals for their suitability as livevirus vaccines (Tab. II). As in other herpesviruses, deletion of the TK gene led to a marked attenuation, which was also the case after deletion of $\mathrm{gG}$, or UL47 $[40,41 \mathrm{bis}, 79]^{5}$. Deletion of $\mathrm{gJ}$ or the ILTV-specific UL0 gene rendered ILTV almost completely apathogenic for chickens (Fig. 1A) [26, 92]. In contrast, dUTPase negative ILTV was shown to retain a considerable virulence after intratracheal application of high virus doses [25].

\footnotetext{
${ }^{5}$ Wild M.A., Cochran M.D., 2001, US patent No. $6,875,856$.
} 
Nevertheless, this virus may be usable for mass vaccination with low amounts of virus. Irrespective of their different residual virulence, which remains to be evaluated in detail in parallel immunization experiments with identical virus doses, all tested ILTV recombinants were able to confer solid protection against challenge infections with virulent ILTV (see e.g. Fig. 1B) and, therefore, should replace the genetically ill-defined vaccines currently in use. An additional advantage of ILTV recombinants with deletions of immunogenic glycoproteins like $\mathrm{gJ}$, and possibly also $\mathrm{gG}$, would be their suitability as marker vaccines, which permit serological differentiation of field-virus infected from vaccinated animals (DIVA strategy) [89] on the basis of the presence or absence of antibodies against the respective viral gene product [26].

\section{ILTV AS A VECTOR FOR ANTIGENS OF OTHER CHICKEN PATHOGENS}

Since ILTV vaccines are suitable for mass application by aerosol or drinking water [39], they may also be useful vectors for immunogenic proteins of other chicken pathogens. Besides the genes encoding the fusion protein of Newcastle disease virus and $\mathrm{gB}$ of $\mathrm{MDV}^{3}$, the $\mathrm{H} 5$ and $\mathrm{H} 7$ hemagglutinin (HA) genes of highly pathogenic avian influenza viruses (HPAIV) were successfully expressed in ILTV recombinants lacking the dUTPase gene or UL0 $[28,61$, 92]. Animal trials with the latter constructs induced ILTV- and HA-specific antibodies and revealed a good protection of immunized chickens against challenge infections with virulent ILTV, as well as with HPAIV of the respective serotypes (Fig. 5A). Protection against fowl plague was comparable to that obtained with inactivated AIV preparations which, however, require subcutaneous or intramuscular application.
Furthermore, epidemiological control of avian influenza in the field by serology is more difficult after vaccination with complete AIV. In contrast, the use of vector based or subunit vaccines containing HA as the only AIV component would allow differentiation of vaccinated from naturally infected animals using serological tests detecting antibodies against other influenza virus proteins like neuraminidase or nucleoprotein (NP) [11, 83, 93]. As expected, NP-specific antibodies were not found in chickens immunized with HAexpressing ILTV but became detectable after challenge with HPAIV, although no clinical signs were observed (Fig. 5B).

These results clearly demonstrate that attenuated ILTV mutants are useful viral vectors, which may also be used for expression of immunogenic proteins of other chicken pathogens like infectious bronchitis virus, bursal disease virus or fowlpox virus, and also of bacteria or parasites. Further experiments are needed to clarify whether these ILTV-based vector vaccines are also suitable for mass administration via aerosol or drinking water, and whether they are effective in the presence of maternally derived or vaccination-induced antiILTV immunity.

\section{CONCLUSION}

ILTV is significantly less well analyzed than several other human and animal herpesviruses. Although its basic parameters reflect its inclusion in the Alphaherpesvirinae subfamily, there are specific features in ILTV that require further analysis. Comparative studies between alphaherpesviruses of the genera Varicellovirus and Simplexvirus, and the phylogenetically distant Iltoviruses could shed more light on the specific co-evolution of herpesviruses with their respective hosts. Furthermore, molecular characterization and genetic engineering of ILTV can contribute 

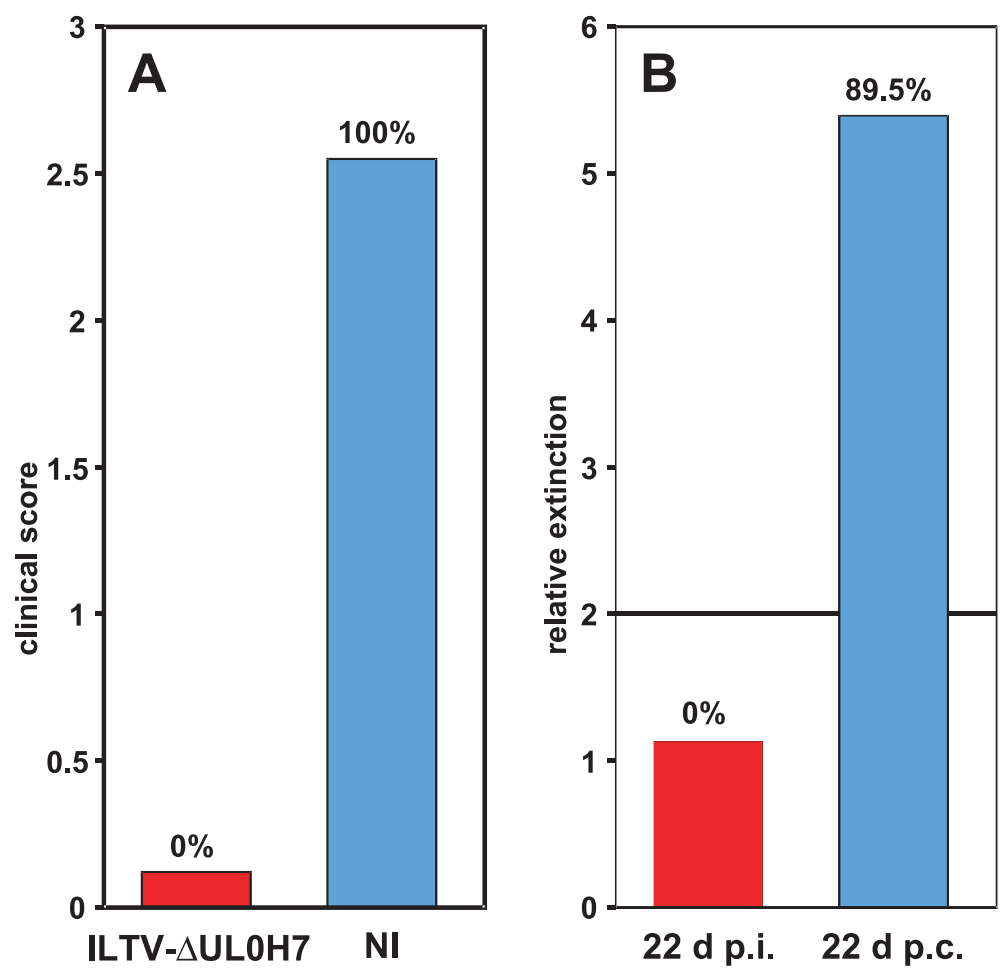

Figure 5. Protection of chickens against fowl plague by marker-vaccination with recombinant ILTV. Ten-week old chickens were immunized by eye-drop application of $10^{5}$ PFU of an attenuated UL0negative ILTV mutant expressing H7-hemagglutinin of HPAIV (ILTV- $\triangle$ ULOH7). After four weeks, vaccinated and control animals (NI) were challenged with $10^{8}$ egg infectious doses of H7N1 HPAIV. (A) Cumulative clinical scores and mortality rates are shown. (B) At days 22 after immunization (p.i.) and challenge (p.c.) the vaccinated animals were tested for influenza virus nucleoproteinspecific serum antibodies by an indirect ELISA [93]. The mean relative extinctions were plotted, and the proportion of positive ( $>2$-fold above negative control) sera indicates that hemagglutininexpressing ILTV might be suitable as marker vaccine against fowl plague. For more details see references [28, 92].

to development of novel, safe and efficacious vaccines not only against infectious laryngotracheitis, but also against other important chicken diseases.

\section{ACKNOWLEDGEMENTS}

Work in the authors' laboratories was supported by the Federal Ministry of Food, Agriculture and Consumer Protection, by the Deutsche Forschungsgemeinschaft (grant FU
395/1) and by Intervet International. The expert technical help of G. Czerwinski, C. Ehrlich, M. Jörn and P. Meyer is greatly appreciated.

\section{REFERENCES}

[1] Abbas F., Andreasen J.R. Jr., Comparison of diagnostic tests for infectious laryngotracheitis, Avian Dis. (1996) 40:290-295.

[2] Abbas F., Andreasen J.R. Jr., Baker R.J., Mattson D.E., Guy J.S., Characterization 
of monoclonal antibodies against infectious laryngotracheitis virus, Avian Dis. (1996) 40:49-55.

[3] Andreasen J.R. Jr., Glisson J.R., Villegas P., Differentiation of vaccine strains and Georgia field isolates of infectious laryngotracheitis virus by their restriction endonuclease fragment patterns, Avian Dis. (1990) 34:646-656.

[4] Bagust T.J., Laryngotracheitis (gallid-1) herpesvirus infection in the chicken. 4. Latency establishment by wild and vaccine strains of ILT virus, Avian Pathol. (1986) 15:581-595.

[5] Barboom S.A., Forgacs A., Solyom F., Development of an inactivated vaccine against laryngotracheitis (ILT) - serological and protection studies, Avian Pathol. (1986) 15:213-221.

[6] Beach J.R., The virus of laryngotracheitis of fowls, Science (1930) 72:633-634.

[7] Ben-Porat T., Veach R.A., Ihara S., Localization of the regions of homology between the genomes of herpes simplex virus type 1 and pseudorabies virus, Virology (1983) 127:194-204.

[8] Benton W.J., Cover M.S., Greene L.M., The clinical and serological response of chickens to certain laryngotracheitis viruses, Avian Dis. (1958) 2:383-396.

[9] Brandly C.A., Bushnell L.D., A report of some investigations of infectious laryngotracheitis, Poult. Sci. (1934) 13:212-217.

[10] Burnet F.M., The propagation of the virus of infectious laryngotracheitis on the CAM of the developing egg, Br. J. Exp. Pathol. (1934) 15:52-55.

[11] Capua I., Terregino C., Cattoli G., Mutinelli F., Rodriguez J.F., Development of a DIVA (Differentiating Infected from Vaccinated Animals) strategy using a vaccine containing a heterologous neuraminidase for the control of avian influenza, Avian Pathol. (2003) 32:47-55.

[12] Chang P.W., Yates V.J., Dardiri A.H., Fry D.E., Some observations of the propagation of infectious laryngotracheitis virus in tissue culture, Avian Dis. (1960) 4:384390.

[13] Chang P.C., Chen K.T., Shien J.H., Shieh H.K., Expression of infectious laryngotracheitis virus glycoproteins in Escherichia coli and their application in enzymelinked immunosorbent assay, Avian Dis. (2002) 46:570-580.
[14] Collins J., Instability of palindromic DNA in Escherichia coli, Cold Spring Harb. Symp. Quant. Biol. (1981) 45:409-416.

[15] Crawshaw G.J., Boycott B.R., Infectious laryngotracheitis in peafowl and pheasants, Avian Dis. (1982) 26:397-401.

[16] Creelan J.L., Calvert V.M., Graham D.A., McCullough S.J., Rapid detection and characterization from field cases of infectious laryngotracheitis virus by realtime polymerase chain reaction and restriction fragment length polymorphism, Avian Pathol. (2006) 35:173-179.

[17] Cruickshank J.G., Berry D.M., Hay B., The fine structure of infectious laryngotracheitis virus, Virology (1963) 20:376378.

[18] Czifra G., Nilsson M., Alexander D.J., Manvell R., Kecskeméti S., Engström B.E., Detection of PMV-1 specific antibodies with a monoclonal antibody blocking enzyme-linked immunosorbent assay, Avian Pathol. (1996) 25:691-703.

[19] Davison A.J., Eberle R., Hayward G.S., McGeoch D.J., Minson A.C., Pellet P.E., Roizman B., Studdert M.J., Thiry E., Family Herpesviridae, in: Fauquet C.M., Mayo M.A., Maniloff J., Desselberger U., Ball L.A. (Eds.), Virus Taxonomy, Academic press, San Diego, 2005, pp. 193-212.

[20] Davison S., Gingerich E.N., Casavant S., Eckroade R.J., Evaluation of the efficacy of a live fowlpox-vectored infectious laryngotracheitis/avian encephalomyelitis virus against ILT viral challenge, Avian Dis. (2006) 50:50-54.

[21] Devlin J.M., Browning G.F., Gilkerson J.R., A glycoprotein I- and glycoprotein E-deficient mutant of infectious laryngotracheitis virus exhibits impaired cell-tocell spread in cultured cells, Arch. Virol. (2006) 151:1281-1291.

[22] Fahey K.J., York J.J., The role of mucosal antibody in immunity to infectious laryngotracheitis virus in chickens, J. Gen. Virol. (1990) 71:2401-2405.

[23] Fuchs W., Mettenleiter T.C., DNA sequence and transcriptional analysis of the UL1 to UL5 gene cluster of infectious laryngotracheitis virus, J. Gen. Virol. (1996) 77:2221-2229.

[24] Fuchs W., Mettenleiter T.C., DNA sequence of the UL6 to UL20 genes of infectious laryngotracheitis virus and characterization of the UL10 gene product as 
a nonglycosylated and nonessential virion protein, J. Gen. Virol. (1999) 80:21732182.

[25] Fuchs W., Ziemann K., Teifke J.P., Werner O., Mettenleiter T.C., The non-essential UL50 gene of avian infectious laryngotracheitis virus encodes a functional dUTPase which is not a virulence factor, $\mathrm{J}$. Gen. Virol. (2000) 81:627-638.

[26] Fuchs W., Wiesner D., Veits J., Teifke J.P., Mettenleiter T.C., In vitro and in vivo relevance of infectious laryngotracheitis virus $\mathrm{gJ}$ proteins that are expressed from spliced and nonspliced mRNAs, J. Virol. (2005) 79:705-716.

[27] Fuchs W., Mettenleiter T.C., The nonessential UL49.5 gene of infectious laryngotracheitis virus encodes an O-glycosylated protein which forms a complex with the non-glycosylated UL10 gene product, Virus Res. (2005) 112:108-114.

[28] Fuchs W., Veits J., Mettenleiter T.C., Recombinant viruses of poultry as vector vaccines against fowl plague, Berl. Münch. Tierärztl. Wochenschr. (2006) 119:160-166.

[29] Gelenczei E.F., Marty E.W., Strain stability and immunologic characteristics of tissue-culture modified infectious laryngotracheitis virus, Avian Dis. (1965) 9:44 56.

[30] Granzow H., Klupp B.G., Fuchs W., Veits J., Osterrieder N., Mettenleiter T.C., Egress of alphaherpesviruses: comparative ultrastructural study, J. Virol. (2001) 75:3675-3684.

[31] Griffin A.M., Identification of 21 genes of infectious laryngotracheitis virus using random sequencing of genomic DNA, J. Gen. Virol. (1989) 70:3085-3089.

[32] Griffin A.M., The complete sequence of the capsid p40 gene from infectious laryngotracheitis virus, Nucleic Acids Res. (1990) 18:3664.

[33] Griffin A.M., Boursnell M.E.G., Analysis of the nucleotide sequence of DNA from the region of the thymidine kinase gene of infectious laryngotracheitis virus; potential evolutionary relationships between the herpesvirus subfamilies, J. Gen. Virol. (1990) 71:841-850.

[34] Griffin A.M., The nucleotide sequence of the glycoprotein $\mathrm{gB}$ of infectious laryngotracheitis virus: analysis and evolutionary relationship to the homologous gene from other herpesviruses, J. Gen. Virol. (1991) 72:393-398.

[35] Guo P., Scholz E., Turek J., Nodgreen R., Maloney B., Assembly pathway of avian infectious laryngotracheitis virus, Am. J. Vet. Res. (1993) 54:2031-2039.

[36] Guy J.S., Barnes H.J., Morgan L.M., Virulence of infectious laryngotracheitis viruses: comparison of modified-live vaccine viruses and North Carolina field isolates, Avian Dis. (1990) 34:106-113.

[37] Guy J.S., Barnes H.J., Smith L.G., Increased virulence of modified-live infectious laryngotracheitis vaccine virus following bird-to-bird passage, Avian Dis. (1991) 35:348-355.

[38] Guy J.S., Barnes H.J., Smith L.G., Rapid diagnosis of infectious laryngotracheitis using a monoclonal antibody-based immunoperoxidase procedure, Avian Pathol. (1992) 21:77-86.

[39] Guy J.S., Bagust T.J., Laryngotracheitis, in: Saif Y.M., Barnes H.J., Glisson J.R., Fadly A.M., McDougald L.R., Swayne D.E. (Eds.), Diseases of poultry, Iowa State Press, Ames, 2003, pp.121-134.

[40] Han M.G., Kweon C.H., Mo I.P., Kim S.J., Pathogenicity and vaccine efficacy of a thymidine kinase gene deleted infectious laryngotracheitis virus expressing the green fluorescent protein gene, Arch. Virol. (2002) 147:1017-1031.

[41] Helferich D., Veits J., Mettenleiter T.C., Fuchs W., Identification of trenscripts and protein products thr UL31, UL37, UL46, UL47, UL49 and U54 gene homologues of avion infections laryngotracheitis virus, J. Gen. Virol. (2007) 88:719-731.

[41bis] Helferich D., Veits J., Teifke J.P., Mettenleiter T.C., Fuchs W., The UL47 gene of avion infections laryngotracheitis virus is not essential for in vitro replication but is relevant for virulence in chickens, J. Gen. Virol. (2007) 88:732734.

[42] Hitchner S.B., Shea C.A., White P.G., Studies on a serum neutralization test for the diagnosis of laryngotracheitis in chickens, Avian Dis. (1958) 2:258-269.

[43] Hitchner S.B., Fabicant J., Bagust T.J., A fluorescent-antibody study of the pathogenesis of infectious laryngotracheitis, Avian Dis. (1977) 21:185-194.

[44] Hughes C.S., Gaskell R.M., Jones R.C., Bradbury J.M., Jordan F.T.W., Effects of 
certain stress factors on the re-excretion of infectious laryngotracheitis virus from latently infected carrier birds, Res. Vet. Sci. (1989) 46:274-276.

[45] Johnson M.A., Prideaux C.T., Kongsuwan K., Sheppard M., Fahey K.J., Gallid herpesvirus 1 (infectious laryngotracheitis virus): cloning and physical maps of the SA-2 strain, Arch. Virol. (1991) 119:181198.

[46] Johnson M.A., Prideaux C.T., Kongsuwan K., Tyack S.G., Sheppard M., ICP27 immediate early gene, glycoprotein $\mathrm{K}(\mathrm{gK})$ and DNA helicase homologues of infectious laryngotracheitis virus (gallid herpesvirus 1) SA-2 strain, Arch. Virol. (1995) 140:623-634.

[47] Johnson M.A., Tyack S.G., Molecular evolution of infectious laryngotracheitis virus (ILTV; gallid herpesvirus 1): an ancient example of the Alphaherpesviridae? Vet. Microbiol. (1995) 46:221-231.

[48] Johnson M.A., Tyack S.G., Prideaux C.T., Kongsuwan K., Sheppard M., Nucleotide sequence of infectious laryngotracheitis virus (gallid herpesvirus 1) ICP4 gene, Virus Res. (1995) 35:193-204.

[49] Johnson M.A., Tyack S.G., Prideaux C.T., Kongsuwan K., Sheppard M., Nucleotide sequence of the left-terminus of infectious laryngotracheitis virus (Gallid herpesvirus 1) SA-2 strain, Arch. Virol. (1997) 142:1903-1910.

[50] Jordan F.T.W., Chubb R.C., The agar gel diffusion technique in the diagnosis of infectious laryngotracheitis (I.L.T.) and its differentiation from fowl pox, Res. Vet. Sci. (1962) 3:245-255.

[51] Kawaguchi T., Nomura K., Hirayama Y., Kitagawa T., Establishment and characterization of a chicken hepatocellular carcinoma cell line, LMH, Cancer Res. (1987) 47:4460-4464.

[52] Kingsley D.H., Hazel J.W., Keeler C.L. Jr., Identification and characterization of the infectious laryngotracheitis virus glycoprotein C gene, Virology (1994) 203:336-343.

[53] Kingsley D.H., Keeler C.L. Jr., Infectious laryngotracheitis virus, an alpha herpesvirus that does not interact with cell surface heparan sulfate, Virology (1999) 256:213-219.

[54] Kirkpatrick N.C., Mahmoudian A., O'Rouke D., Noormohammadia A.H.,
Differentiation of infectious laryngotracheitis virus isolates by restriction fragment length polymorphic analyses of polymerase chain reaction products amplified from multiple genes, Avian Dis. (2006) 50:28-34.

[55] Kongsuwan K., Prideaux C.T., Johnson M.A., Sheppard M., Fahey K.J., Nucleotide sequence of the gene encoding infectious laryngotracheitis virus glycoprotein B, Virology (1991) 184:404-410.

[56] Kongsuwan K., Johnson M.A., Prideaux C.T., Sheppard M., Identification of an infectious laryngotracheitis virus gene encoding an immunogenic protein with a predicted $M_{r}$ of 32 kilodaltons, Virus Res. (1993) 29:125-140.

[57] Kongsuwan K., Johnson M.A., Prideaux C.T., Sheppard M., Use of lambda gt11 and monoclonal antibodies to map the gene for the 60,000 dalton glycoprotein of infectious laryngotracheitis virus, Virus genes (1993) 7:297-303.

[58] Kotiw M., Wilks C.R., May J.T., The effect of serial in vivo passage on the expression of virulence and DNA stability of an infectious laryngotracheitis virus strain of low virulence, Vet. Microbiol. (1995) 45:71-80.

[59] Kramps J.A., Magdalena J., Quak J., Weerdmeester K., Kaashoek M.J., MarisVeldhuis M.A., Rijsewijk F.A., Keil G., van Oirschot J.T., A simple, specific, and highly sensitive blocking enzyme-linked immunosorbent assay for detection of antibodies to bovine herpesvirus 1, J. Clin. Microbiol. (1994) 32:2175-2181.

[60] Leib D.A., Bradbury J.M., Hart C.A., McCarthy K., Genome isomerism in two alphaherpesviruses: herpesvirus saimiri-1 (herpesvirus tamarinus) and avian infectious laryngotracheitis virus, Arch. Virol. (1987) 93:287-294.

[61] Lüschow D., Werner O., Mettenleiter T.C., Fuchs W., Protection of chickens from lethal avian influenza A virus infection by live-virus vaccination with infectious laryngotracheitis virus recombinants expressing the hemagglutinin (H5) gene, Vaccine (2001) 19:4249-4259.

[62] May H.G., Tittsler R.P., Tracheolaryngitis in poultry, J. Am. Vet. Med. Assoc. (1925) 67:229-231.

[63] Mayer V.M., Hetrick F.M., Keenum W.D., DeVolt H.M., Replication of infectious 
laryngotracheitis virus in chicken kidney cell culture, Am. J. Vet. Res. (1967) 28:825-832.

[64] McGeoch D.J., Dalrymple M.A., Davison A.J., Dolan A., Frame M.C., McNab D., Perry L.J., Scott J.E., Taylor P., The complete DNA sequence of the long unique region in the genome of herpes simplex virus type 1, J. Gen. Virol. (1988) 69:1531-1574.

[65] McGeoch D.J., Dolan A., Ralph A.C., Toward a comprehensive phylogeny for mammalian and avian herpesviruses, J. Virol. (2000) 74:10401-10406.

[66] Messerle M., Crnkovic I., Hammerschmidt W., Ziegler H., Koszinowski U.H., Cloning and mutagenesis of a herpesvirus genome as an infectious bacterial artificial chromosome, Proc. Natl. Acad. Sci. USA (1997) 94:14759-14763.

[67] Mettenleiter T.C., Herpesvirus assembly and egress, J. Virol. (2002) 76:1537-1547.

[68] Meulemans G., Halen P., Enzyme-linked immunosorbent assay (ELISA) for detecting infectious laryngotracheitis viral antibodies in chicken serum, Avian Pathol. (1982) 11:361-368.

[69] Okamura H., Sakaguchi M., Honda T., Taneno A., Matsuo K., Yamada S., Construction of recombinant infectious laryngotracheitis virus expressing the LacZ gene of $E$. coli with thymidine kinase gene, J. Vet. Med. Sci. (1994) 56:799-801.

[70] Poulsen D.J., Burton C.R., O’Brian J.J., Rabin S.J., Keeler C.L. Jr., Identification of the infectious laryngotracheitis virus glycoprotein $\mathrm{gB}$ gene by the polymerase chain reaction, Virus Genes (1991) 5:335347.

[71] Poulsen D.J., Keeler C.L. Jr., Characterization of the assembly and processing of infectious laryngotracheitis virus glycoprotein B, J. Gen. Virol. (1997) 78:29452951.

[72] Prideaux C.T., Kongsuwan K., Johnson M.A., Sheppard M., Fahey K.J., Infectious laryngotracheitis virus growth, DNA replication, and protein synthesis, Arch. Virol. (1992) 123:181-192.

[73] Reynolds H.A., Watrach A.M., Hanson L.E., Development of the nuclear inclusion bodies of infectious laryngotracheitis, Avian Dis. (1968) 12:332-347.
[74] Roizman B., Knipe D.M., Herpes simplex viruses and their replication, in: Knipe D.M., Howley P.M. (Eds.), Fields Virology, Lippincott Williams \& Wilkins, Philadelphia, 2001, pp. 2399-2459.

[75] Roizman B., Pellett P.E., The family Herpesviridae: A brief introduction, in: Knipe D.M., Howley P.M. (Eds.), Fields Virology, Lippincott Williams \& Wilkins, Philadelphia, 2001, pp. 2381-2397.

[76] Saif Y.M., Rosenberger J.K., Cloud S.S., Wild M.A., McMillen J.K., Schwartz R.D., Efficacy and safety of a recombinant herpesvirus of turkeys containing genes from infectious laryngotracheitis virus, in: Proc. Am. Vet. Med. Assoc., Minneapolis, 1994, p. 154

[77] Samberg Y., Aronovici I., The development of a vaccine against avian infectious laryngotracheitis. 1. Modification of a laryngotracheitis virus, Refu. Vet. (1969) 26:54-59.

[78] Schnitzlein W.M., Radzevicius J., Tripathy D.N., Propagation of infectious laryngotracheitis virus in an avian liver cell line, Avian Dis. (1994) 38:211-217.

[79] Schnitzlein W.M., Winans R., Ellsworth S., Tripathy D.N., Generation of thymidine kinase-deficient mutants of infectious laryngotracheitis virus, Virology (1995) 209:304-314.

[80] Scholz E., Welniak E., Nyholm T., Guo P., An avian hepatoma cell line for the cultivation of infectious laryngotracheitis virus and for the expression of foreign genes with a mammalian promoter, J. Virol. Methods (1993) 43:273-286.

[81] Scholz E., Porter R.E., Guo P., Differential diagnosis of infectious laryngotracheitis from other avian respiratory diseases by a simplified PCR procedure, J. Virol. Methods (1994) 50:313-322.

[82] Schumacher D., Tischer B.K., Fuchs W., Osterrieder N., Reconstitution of Marek's disease virus serotype 1 (MDV-1) from DNA cloned as a bacterial artificial chromosome and characterization of a glycoprotein B-negative MDV-1 mutant, J. Virol. (2000) 74:11088-11098.

[83] Shafer A.L., Katz J.B., Eernisse K.A., Development and validation of a competitive enzyme-linked immunosorbent assay for detection of type A influenza antibodies in avian sera, Avian Dis. (1998) 42:28-34. 
[84] Shibley G.P., Luginbuhl R.E., Helmboldt C.F., Study of infectious laryngotracheitis virus. I. Comparison of serologic and immunogenic properties, Avian Dis. (1962) 6:59-71.

[85] Sun Y., MacLean A.R., Dargan D., Brown S.M., Identification and characterization of the protein product of gene 71 in equine herpesvirus 1, J. Gen. Virol. (1994) 75:3117-3126.

[86] Telford E.A., Watson M.S., McBride K., Davison A.J., The DNA sequence of equine herpesvirus-1, Virology (1992) 189:304-316.

[87] Thureen D.R., Keeler C.L. Jr., Psittacid herpesvirus 1 and infectious laryngotracheitis virus: comparative genome sequence analysis of two avian alphaherpesviruses, J. Virol. (2006) 80:7863-7872.

[88] Tong G.Z., Zhang S.J., Meng S.S., Wang L., Qiu H.J., Wang Y.F., Yu L., Wang M., Protection of chickens from infectious laryngotracheitis with a recombinant fowlpox virus expressing glycoprotein B of infectious laryngotracheitis virus, Avian Pathol. (2001) 30:143-148.

[89] Van Oirschot J.T., Diva vaccines that reduce virus transmission, J. Biotechnol. (1999) 73:195-205.

[90] Veits J., Köllner B., Teifke J.P., Granzow H., Mettenleiter T.C., Fuchs W., Isolation and characterization of monoclonal antibodies against structural proteins of infectious laryngotracheitis virus, Avian Dis. (2003) 47:330-342.

[91] Veits J., Mettenleiter T.C., Fuchs W., Five unique open reading frames of infectious laryngotracheitis virus are expressed during infection but are dispensable for virus replication in cell culture, J. Gen. Virol. (2003) 84:1415-1425.

[92] Veits J., Lüschow D., Kindermann K., Werner O., Teifke J.P., Mettenleiter T.C., Fuchs W., Deletion of the non-essential ULO gene of infectious laryngotracheitis (ILT) virus leads to attenuation in chickens, and ULO mutants expressing influenza virus haemagglutinin (H7) protect against ILT and fowl plague, J. Gen. Virol. (2003) 84:3343-3352.

[93] Veits J., Wiesner D., Fuchs W., Hoffmann B., Granzow H., Starick E., Mundt
E., Schirrmeier H., Mebatsion T., Mettenleiter T.C., Römer-Oberdörfer A., Newcastle disease virus expressing H5 hemagglutinin gene protects chickens against Newcastle disease and avian influenza, Proc. Natl. Acad. Sci. USA (2006) 103:8197-9202.

[94] Watrach A.M., Hanson L.E., Watrach M.A., The structure of infectious laryngotracheitis virus, Virology (1963) 21:601608.

[95] Wild M.A., Cook S., Cochran M., A genomic map of infectious laryngotracheitis virus and the sequence and organization of genes present in the unique short and flanking regions, Virus Genes (1996) 12:107-116.

[96] Williams R.A., Benett M., Bradbury J.M., Gaskell R.M., Jones R.C., Jordan F.T.W., Demonstration of sites of latency of infectious laryngotracheitis virus using the polymerase chain reaction, J. Gen. Virol. (1992) 73:2415-2420.

[97] Winterfield R.W., So I.G., Susceptibility of turkeys to infectious laryngotracheitis, Avian Dis. (1968) 12:191-202.

[98] York J.J., Fahey K.J., Diagnosis of infectious laryngotracheitis using a monoclonal antibody ELISA, Avian Pathol. (1988) 17:173-182.

[99] York J.J., Sonza S., Brandon M.R., Fahey K.J., Antigens of infectious laryngotracheitis herpesvirus defined by monoclonal antibodies, Arch. Virol. (1990) 115:147_ 162.

[100] York J.J., Fahey K.J., Vaccination with affinity-purified glycoproteins protects chickens against infectious laryngotracheitis herpesvirus, Avian Pathol. (1991) 20:693-704.

[101] Ziemann K., Mettenleiter T.C., Fuchs W., Gene arrangement within the unique long genome region of infectious laryngotracheitis virus is distinct from that of other alphaherpesviruses, J. Virol. (1998) 72:847-852.

[102] Ziemann K., Mettenleiter T.C., Fuchs W., Infectious laryngotracheitis herpesvirus expresses a related pair of unique nuclear proteins which are encoded by spilt genes located at the right end of the $\mathrm{U}_{\mathrm{L}}$ genome region, J. Virol. (1998) 72:6867-6874 